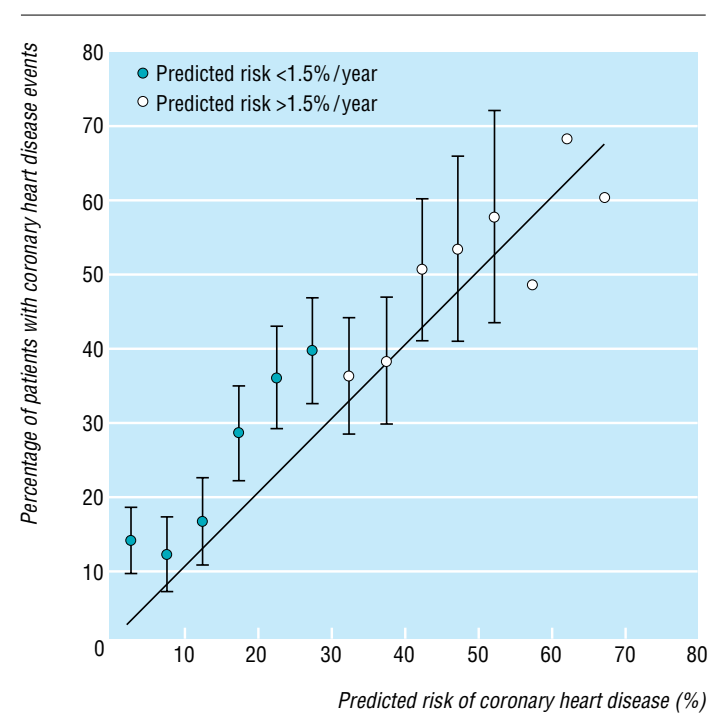

Number of coronary heart disease events observed in the Whickham study compared with number of events predicted by Framingham model in participants with predicted risk below or above $1.5 \% / y e a r$. In the highest risk groups the small number of participants prevents calculation of confidence intervals

$\mathrm{P}<0.0001)$. When individual variables were subjected to logistic regression, male sex, age, blood pressure, smoking status, and cholesterol concentrations were all significant predictors of heart disease but when corrected for the Framingham risk score no single factor remained predictive on its own.

The figure shows the number of coronary events predicted by the Framingham model and the number observed during follow up. The agreement is good at a predicted event rate above $30 \%$ (1.5\% per year), with no significant difference between the observed and expected event rates $(\mathrm{P}=0.85)$. However, at lower event rates the predictive model significantly underestimates the number of observed events $(\mathrm{P}<0.01)$. The wide confidence intervals indicate that there is significant overlap between risk scores in those participants who developed heart disease and those who did not.

\section{Comment}

These results confirm that the Framingham model reliably predicts the absolute risk of heart disease in white men and women in the United Kingdom when the annual risk is above $1.5 \%$, but the model underestimates the risk when the absolute risk is lower. This is consistent with studies that have shown that the model is inaccurate when applied to low risk populations. ${ }^{5} \mathrm{We}$ might have achieved a closer fit with the model by measuring concentrations of high density lipoprotein cholesterol and using a 4 to 12 year follow up period similar to that from which the model was derived. Nevertheless, the recommended threshold for treatment with lipid lowering drugs is based on an annual risk of $3 \%$ per year, ${ }^{1}$ so the Framingham model can be used in clinical practice in the UK population.

We would like to thank Drs M Tunbridge and D Appleton for providing access to the data from the Whickham study and Professor Gilbert MacKenzie for helpful comments on the manuscript.

Contributors: SR and RHN developed the computer database and used it to analyse the data, as suggested by MPJV. MPJV and JMF provided the data. PC provided advice on data analysis and presentation. The paper was written by all of the authors. RHN is guarantor for the study.

Funding: The Department of Health and Newcastle District Research Committee provided financial support for this study.

Competing interests: None declared.

1 Ramsay LE, Haq IU, Jackson PR, Yeo WW, Pickin DM, Payne JN. Targeting lipid-lowering drug therapy for primary prevention of coronary disease: an updated Sheffield table. Lancet 1996;348:387-8.

2 Chambless LE, Dobson AJ, Patterson CC, Raines B. On the use of a logistic score in predicting risk of coronary heart disease. Stat Med 1990;9:385-96

3 Vanderpump MJP, Tunbridge WMG, French JM, Appleton D, Bates D, Clark F, et al. The development of ischemic heart disease in relation to autoimmune thyroid disease in a 20 year follow-up of an English community. Thyroid 1996;6:155-60.

4 Anderson KM, Wilson PWF, Odell PM, Kannel WB. An updated coronary risk profile: a statement for health professionals. Circulation 1991;3:356-62. (American Heart Association statement.)

5 Kannel WB, Larson M. Long-term epidemiologic prediction of coronary disease. Cardiology 1993;82:137-52.

(Accepted 19July 1999)

\title{
Should treatment recommendations for lipid lowering drugs be based on absolute coronary risk or risk reduction?
}

\author{
S Ramachandran, J M French, M P J Vanderpump, P Croft, R H Neary
}

Current guidelines for prescribing lipid lowering drugs are based on an individual's risk of coronary heart disease rather than on the reduction in risk that treatment may bring. We report a strategy for making treatment decisions that combines computer assisted calculation of absolute risk with an estimate of benefit to the patient from treatment.

\section{Subjects, methods, and results}

During a period of 14 months, 17 randomly selected general practices (63 practitioners) in north Stafford- shire were asked to send to the department of clinical biochemistry their requests for coronary heart disease risk assessment on patients being considered for lipid lowering drug treatment.

We used the Framingham statistical model to estimate a patient's absolute risk of coronary heart disease over five years. The reduction in risk that treatment would bring over the next five years was calculated from the product of the absolute five year risk and the risk reduction observed in clinical trials or meta-analysis. The reduction in risk associated with cholesterol lowering drugs was $0.31,{ }^{1}$ which was adjusted
Editorial by Jackson

Department of Clinical

Biochemistry, North Staffordshire Hospital, Stoke on Trent ST4 7PA

S Ramachandran senior registrar, chemical pathology R H Neary consultant, chemical pathology

continued over

BMJ 2000;320:677-9 
Department of

Epidemiology,

North Staffordshire

Hospital

$\mathrm{P}$ Croft

professor

Department of Medical Statistics,

University of

Newcastle,

Newcastle upon

Tyne NE2 4HH

$\mathrm{J} M$ French

research associate

Department of Endocrinology, Royal Free

Hospital, London NW3 2QG

M P J Vanderpump consultant endocrinologist

Correspondence to: R H Neary

nearrh@netscape.net for the patient's age in line with a meta-analysis showing less benefit with increasing age. ${ }^{2}$ The reduction in risk was calculated as the absolute five year risk $\times 0.31 \times$ age factor (the age factor $=0.02357(\mathrm{a})^{2}-3.719(\mathrm{a})+165.3$, where $(\mathrm{a})=$ the patient's age, calculated from $\left.{ }^{2}\right)$.

A database running on Microsoft Access (version 7 for Windows 95) was developed. This calculated absolute risk, risk reduction (and number needed to treat), and the mean five year risk in the local population for that age and sex.

Patients were grouped according to whether they would be recommended for treatment because $(a)$ their absolute risk of coronary heart disease was greater than $15 \%$ in five years; $(b)$ treatment would reduce their absolute risk of heart disease by more than $4.45 \%$ over five years (equivalent to the treatment benefit in the high risk group in the Scottish study ${ }^{3}$ ); or (c) they met both criteria. The Mann-Whitney U test and the $\chi^{2}$ test were used to compare the levels of risk factors in these groups.

We received assessment requests for 1320 patients. Patients with vascular disease, aged over 75 years, or already taking lipid lowering drugs were excluded (393 patients). The remaining 927 patients included 484 men (55\%), 247 smokers (27\%), and 139 with diabetes $(15 \%)$. The figure shows the breakdown of risk factors in the groups of patients for whom treatment would be recommended.

Patients recommended for treatment because of absolute risk but not benefit $(n=34)$ were less likely to be hyperlipidaemic than those recommended because of benefit but not risk $(n=17)$. The former group had a lower concentration of total cholesterol (mean difference $0.97 \mathrm{mmol} / \mathrm{l}, \mathrm{P}=0.007)$; a higher concentration of high density lipoprotein cholesterol $(0.14 \mathrm{mmol} / \mathrm{l}$,
$P=0.05)$; a lower ratio of total cholesterol to high density lipoprotein cholesterol $(1.84, \mathrm{P}=0.0007)$; and a lower concentration of triglycerides $(2.2 \mathrm{mmol} / \mathrm{l}$, $\mathrm{P}=0.04$ ) than patients recommended for treatment on the basis of benefit. They were also older (mean difference 19.9 years, $\mathrm{P}<0.0001)$ and tended to have a higher systolic blood pressure (13.9 $\mathrm{mm} \mathrm{Hg}, \mathrm{P}=0.09)$, although fewer of them smoked $(29.4 \% \approx 70.6 \%$, $\mathrm{P}=0.005)$.

\section{Comment}

Recommendations based on absolute risk may not achieve the most appropriate prescribing as lipid lowering drugs may be given to patients whose main coronary risk factor is not hyperlipidaemia. By ignoring risk reduction, doctors may miss an opportunity for coronary prevention in younger people whose absolute risk threshold in five years is below $15 \%$. These patients stand to gain more through treatment of their main risk factor (hyperlipidaemia), particularly when this is viewed in the context of their greater life expectancy.

We calculate and report benefit from other measures too, using risk reductions of $16 \%$ for antihypertensive drugs, ${ }^{4} 22.4 \%$ for aspirin, ${ }^{5}$ and $45 \%$ for stopping smoking (a conservative estimate). Reporting a patient's risk reduction for several measures provides doctors with more objective information to help them choose the most appropriate treatment. In addition, computer networking provides an opportunity for national guidelines to be developed and updated along similar lines.

ADDENDUM-The recent analysis of the statin trials by LaRosa (JAMA 1999;282:2340-6), published

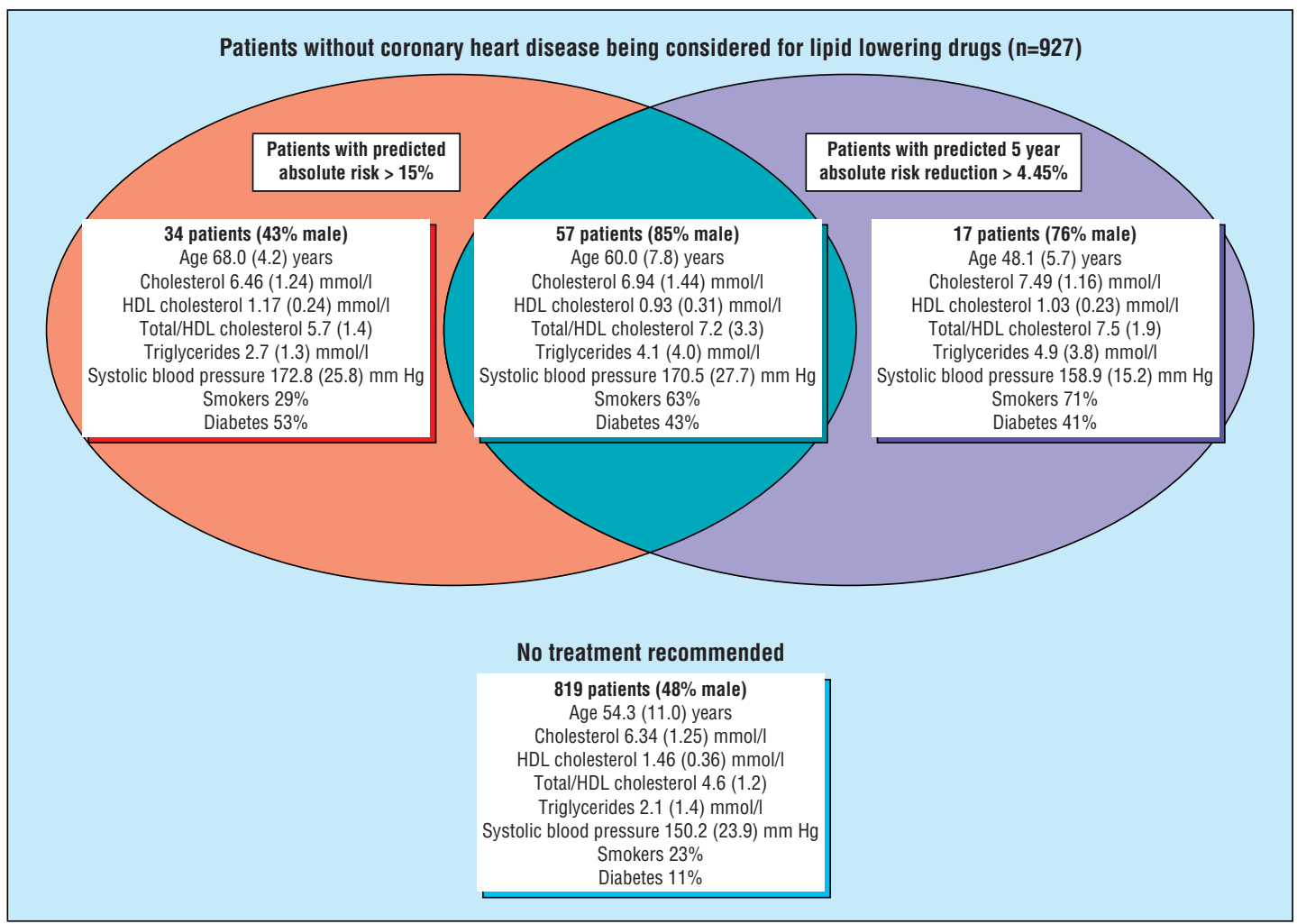

Coronary risk factors in patients being considered for lipid lowering drugs. Values are means (SD) 
since this article was accepted for publication, suggests no difference in relative risk reduction in subjects older or younger than 65 years. The conclusion from this analysis may not necessarily apply across the wider age range commonly encountered by those running primary prevention clinics; nevertheless, at this stage more data are required to establish whether the benefits of lipid lowering therapy are age related.

Contributors: RHN and SR set up the study, developed the database, and evaluated the data with PC. The report was written jointly by all authors.

We thank Dr Giri Rajaratnam, Director of Heath Policy and Public Health Medicine for supporting this programme.
Funding: North Staffordshire Health authority. Competing interests: None declared.

1 Shepherd J, Cobbe SM, Ford I, Isles CG, Lorimer AR, Macfarlane PW, et al. Prevention of coronary heart disease with pravastatin in men with hypercholesterolemia. N Engl J Med 1995:333:1301-7.

2 Law MR, Wald NJ, Thompson SG. By how much and how quickly does reduction in serum cholesterol lower risk of ischaemic heart disease? $B M J$ 1994:308:367-72.

3 West of Scotland Coronary Prevention Group. West of Scotland coronary prevention study: identification of high-risk groups and comparison with other cardiovascular intervention trials. Lancet 1996;348:1339-42.

4 Collins R, MacMahon S. Blood pressure, antihypertensive drug treatment and the risks of stroke and coronary heart disease. $\mathrm{Br}$ Med Bull 1994;50:272-98.

5 Medical Research Council's General Practice Research Framework. Thrombosis prevention trial: randomised trial of low-intensity oral anticoagulation with warfarin and low-dose aspirin in the primary prevention of ischaemic heart disease in men at increased risk. Lance 1998;351:233-41

(Accepted 30 July 1999)

\section{Drug points}

\section{Allergy associated with ciprofloxacin}

P Burke, S R Burne, St Bartholomew's Medical Centre, Oxford OX4 1XB, K J Cann, Department of Public Health, Oxfordshire Health Authority, Headington, Oxford OX3 7LG

Meningococcal infection can be life threatening. Most infections are sporadic, although clusters do occur, particularly in teenagers. The management of clusters includes giving antibiotics to a defined group. Vaccination has a role in clusters of meningococcal serogroup $\mathrm{C}$ infection. Although ciprofloxacin $500 \mathrm{mg}$ orally is not licensed for prophylaxis against meningococcal disease, it is used because it reduces meningococcal carriage, ${ }^{1}$ can be given as a single dose, and, unlike rifampicin, does not interact adversely with the contraceptive pill. ${ }^{2}$ We report on anaphylactoid reactions to ciprofloxacin in three students and a close contact with meninogoccal infection (table).

Two cases (one fatal) of meningococcal infection occurred in first year university students within 12 days of each other. Ciprofloxacin $500 \mathrm{mg}$ orally was offered to all the 4253 students in their first year at the university; around 3200 accepted.

Three cases of anaphylactoid reaction occurred-a rate of about 1:1000, much higher than the 1:100 000 quoted (12 cases in a population of 972000$).^{3}$ Two of the three students had no history of atopic illness. All three students and the contact recovered. Additional adverse reactions were mild skin rashes in three students and nausea and vomiting in two.

A high rate of serious adverse events must be balanced by clear benefits to the target group. Ciprofloxacin clears meningococcal carriage so reducing transmission to a susceptible host. As carriers do not become cases the benefits from ciprofloxacin are for the community not the individual. The risk of a second case of infection among close contacts is 500 to 1000 times higher than in the general population. ${ }^{4}$ The risk of a third case in a student population that has already had two cases is unknown.

1 Gaunt PN, Lambert BE. Single dose ciprofloxacin for the eradication of pharyngeal carriage of Neisseria meningitidis. J Antimicrob Chemother 1988;21:489-96.

2 Borcherding SM, Bastian TL, Self TH, Abou-Shala N, LeDuc BW, LaLonde DW. Two and four day rifampicin chemoprophylaxis regimens induce oxidative metabolism. Antimicrob Agents Chemo 1993;36:1553-8.

3 Davis H, McGoodwin E, Greene Reed T. Anaphylactoid reactions reported after treatment with ciprofloxacin. Ann Intern Med 1989;111:1041-3.

4 Hastings L, Stuart J, Andrews N, Begg N. A retrospective survey of clusters of meningococcal disease in England and Wales, 1993 to 1995: estimated risks of further cases in household and educational settings. $C D R$ Review 1997;7:R195-200.

\section{Serious allergic reactions to ciprofloxacin}

\begin{tabular}{|c|c|c|c|c|c|}
\hline Patient (sex) & $\begin{array}{c}\text { Age } \\
\text { (years) }\end{array}$ & $\begin{array}{c}\text { Onset } \\
\text { (minutes) }\end{array}$ & Symptoms & Findings & Treatment \\
\hline \multicolumn{6}{|l|}{ Student } \\
\hline 1 (male) & 21 & 30 & $\begin{array}{l}\text { Tight and hoarse throat, } \\
\text { swelling of eyes }\end{array}$ & $\begin{array}{l}\text { Blood pressure } 150 / 100 \mathrm{~mm} \mathrm{Hg} \text {, } \\
\text { peak flow } 5501 / \mathrm{m}\end{array}$ & Adrenaline intramuscularly and chlorpheniramine orally \\
\hline 2 (female) & 20 & $20-30$ & Itchy rash, tight throat & $\begin{array}{l}\text { Blood pressure } 120 / 80 \mathrm{~mm} \mathrm{Hg} \text {, } \\
\text { peak flow } 4501 / \mathrm{m}\end{array}$ & Adrenaline intramuscularly and chlorpheniramine orally \\
\hline $3^{*}$ (female) & 19 & $3 \dagger$ & $\begin{array}{l}\text { Dyspnoea, tight throat, } \\
\text { swelling of eyes, cough }\end{array}$ & $\begin{array}{l}\text { Peak flow } 3001 / \mathrm{m} \text {, heart rate } \\
160,100 \% \text { saturation }\end{array}$ & $\begin{array}{l}\text { Adrenaline intramuscularly, chlorpheniramine orally, } \\
\text { and salbutamol by nebuhaler. } \\
\text { Admitted to hospital for } 2 \text { days }\end{array}$ \\
\hline
\end{tabular}

\section{Contact}

$1 \neq$ (male) $\quad 19 \quad 30 \quad$ Swelling of face and eyes -

